(C) 2022, The Authors. Published by Elsevier Inc. and Fass Inc. on behalf of the American Dairy Science Association ${ }^{\circledR}$. This is an open access article under the CC BY license (http://creativecommons.org/licenses/by/4.0/).

\title{
Occurrence and greater intensity of estrus in recipient lactating dairy cows improve pregnancy per embryo transfer
}

\author{
A. M. L. Madureira, ${ }^{1} \oplus$ T. A. Burnett, ${ }^{1,2} \oplus$ J. C. S. Marques, ${ }^{1} \odot$ A. L. Moore, ${ }^{1} \odot$ S. Borchardt, ${ }^{3} \odot$ W. Heuwieser, ${ }^{3} \odot$ \\ T. G. Guida, ${ }^{4}$ J. L. M. Vasconcelos, ${ }^{4}$ (1) C. F. Baes, ${ }^{5,6}{ }^{(1)}$ and R. L. A. Cerri ${ }^{1 *}$ (1) \\ ${ }_{1}^{1}$ Applied Animal Biology, Faculty of Land and Food Systems, University of British Columbia, Vancouver, BC, Canada, V6T 1 Z4 \\ ${ }^{2}$ Ridgetown Campus, University of Guelph, Ridgetown, ON, Canada, NOP 2C0 \\ ${ }^{3}$ Clinic of Animal Reproduction, Freie Universitaet Berlin, Berlin, Germany, 14163 \\ ${ }^{4}$ Department of Animal Production, São Paulo State University, Botucatu, Brazil 18168-000 \\ ${ }^{5}$ Centre for Genetic Improvement of Livestock, University of Guelph, Guelph, ON, Canada, N1G 2W1 \\ ${ }^{6}$ Institute of Genetics, Vetsuisse Faculty, University of Bern, 3002 Bern, Switzerland
}

\section{ABSTRACT}

The aim of this study was to determine the association between occurrence and intensity of estrous expression with pregnancy success in recipient lactating dairy cows subjected to embryo transfer (ET). Two observational studies were conducted. Holstein cows were synchronized using the same timed ET protocol, based on estradiol and progesterone in both experiments. At $9 \mathrm{~d}$ after the end of the timed ET protocol only animals that had ovulated were implanted with a 7-d embryo [experiment 1 (Exp. 1); $\mathrm{n}=1,401 \mathrm{ET}$ events from 1,045 cows, and experiment 2 (Exp. 2); $\mathrm{n}=1,147$ ET events from 657 cows]. Embryos were produced in vivo (Exp. 1 and Exp. 2) and in vitro (only Exp. 2), then transferred to recipient cows as fresh or frozen-thawed. Pregnancy was confirmed at 29 and $58 \mathrm{~d}$ after the end of timed ET protocol. In Exp. 1, animals had their estrous expression monitored through a tail chalk applied on the tail head of the cows and evaluated daily for chalk removal (no estrus: $100 \%$ of chalk remaining; estrus: $<50 \%$ of chalk remaining). In Exp. 2, cows were continuously monitored by a leg-mounted automated activity monitor. Estrous expression was quantified using the relative increase in physical activity at estrus in relation to the days before estrus. Estrous expression was classified as no estrus $[<100 \%$ relative increase in activity $(\mathrm{RI})]$, weak intensity (100-299\% RI), and strong intensity ( $\geq 300 \% \mathrm{RI})$. Data were analyzed by analysis of variance using mixed linear regression models (GLIMMIX) in SAS (SAS Institute Inc.). A total of $65.2 \%(914 / 1,401)$ and $89.2 \%(1,019 / 1,142)$ of cows from Exp. 1 and Exp.

Received March 10, 2021.

Accepted July 14, 2021.

*Corresponding author: ronaldo.cerri@ubc.ca
2 , respectively, displayed estrus at the end of the ovulation synchronization protocol. In Exp. 1, cows expressing estrus before to ET had greater pregnancy per ET than those that did not $[41.0 \pm 2.3 \%(381 / 914)$ vs. 31.5 $\pm 2.9 \%(151 / 487)$, respectively]. Similarly, in Exp. 2, cows classified in the strong intensity group had greater pregnancy per ET compared with cows in the weak intensity and no estrus groups $[41.3 \pm 2.2 \%(213 / 571)$ vs. $32.7 \pm 2.7 \%(115 / 353)$ vs. $11.3 \pm 3.5 \%(26 / 218)$, respectively]. There was no effect of ET type on pregnancy per ET in Exp. 1. However, in Exp. 2, cows that received an in vivo-produced embryo, either fresh or frozen, had greater pregnancy per ET compared with cows that received in vitro-produced embryo. Cows receiving embryos in the early blastocyst and blastocyst stage had greater fertility compared with cows receiving embryos in the morula stage. There was an interaction between the occurrence of estrus and the stage of embryo development on pregnancy per ET, cows which displayed estrus and received a morula or early blastocyst had greater pregnancy per ET than cows that did not display estrus. In conclusion, the occurrence and the intensity of estrous expression improved pregnancy per ET in recipient lactating dairy cows and thus could be used as a tool to assist in the decision making of reproduction strategies in dairy farms.

Key words: embryo transfer, estrous expression, automated activity monitors, pregnancy per ET

\section{INTRODUCTION}

Embryo transfer (ET) was developed in the 1970s (Hasler, 2014) and has become an important breeding technology for the dairy industry associated with accelerated gains in genetic progress (Jaton et al., 2016, 2019). Studies have shown that ET can be applied to dairy herds to improve fertility compared with AI 
(Chebel et al., 2008; Vasconcelos et al., 2011). Embryo transfer can minimize problems of poor-quality oocytes and embryos that result from extended follicular dominance (Cerri et al., 2009; Santos et al., 2010), lower concentrations of progesterone (P4) during the growth of the pre-ovulatory follicle (Wiltbank et al., 2012), as well as minimize issues during early embryonic development (Mann et al., 2006). Embryo transfer reduces the negative effects of heat stress (Hansen, 2007) on fertility (Drost et al., 1999; Al-Katanani et al., 2002; Vasconcelos et al., 2006) as embryos are placed in the uterus at a developmental stage less susceptible to the harmful effects of heat stress. Overall, factors affecting pregnancy outcomes after ET in dairy cattle have been extensively studied. Few studies, however, have focused on the effect of the occurrence and intensity of estrous expression in recipient lactating dairy cows and its association with pregnancy outcomes from ET.

Occurrence of estrus, as well as the intensity of estrous expression, have been shown to have positive effects on fertility from spontaneous estrus detected by automated activity monitors (AAM; Burnett et al., 2018; Tippenhauer et al., 2021a,b) and timed AI programs (Pereira et al., 2016; Madureira et al., 2019). Similarly, the occurrence of estrus in recipient cows appears to increase pregnancy per ET when using either estradiol-based (Pereira et al., 2016) or GnRH-based protocols (Jinks et al., 2013) and has been associated with decreased pregnancy loss after ET (Pereira et al., 2016).

A study by Madureira et al. (2019) reported that cows with greater intensity of estrous expression have greater concentration of $\mathrm{P} 4$ post-AI and greater pregnancy per AI. Greater pregnancy per ET are associated when embryo transfer occurs with excellent and good quality embryos (Ferraz et al., 2016) and embryos in later stages of embryonic development (Erdem et al., 2020). However, the association of stage of embryo development and the quality of the transferred embryo with the occurrence and intensity of estrous behavior has yet to be studied. Overall, the biological mechanism linking estrous expression and fertility is unclear, but likely associated with the hormonal milieu during diestrus and proestrus, as both progesterone and estradiol play important roles in the development of the oocyte and the receptivity of the uterus while also being associated with differences in the occurrence and expression of estrus (Denis-Robichaud et al., 2018; Madureira et al., 2018).

The main objective of this study was to evaluate the association between occurrence and intensity of estrous expression with the fertility of recipient lactating dairy cows bred using ET technology and to determine if there is an interaction with the stage and quality of the transferred embryo. We hypothesize that the occurrence of estrus and estrus intensity are proportionately associated with improved pregnancy rates (per ET) and reduced pregnancy loss compared with those in animals without signs of estrus. Furthermore, we hypothesize that animals receiving an embryo in a more advanced stage or of greater quality would also have greater pregnancy rates (per ET) and reduced pregnancy loss.

\section{MATERIALS AND METHODS}

Two observational cohort studies were conducted on 2 commercial farms in Brazil (farm A: in São Paulo state, $22^{\circ} 21^{\prime} 25^{\prime \prime} \mathrm{S}, 47^{\circ} 23^{\prime} 03^{\prime \prime} \mathrm{W}$ and farm B: in Minas Gerais state, $\left.19^{\circ} 18^{\prime} 40^{\prime \prime} \mathrm{S} ; 46^{\circ} 02^{\prime} 56^{\prime \prime} \mathrm{W}\right)$. Experiment 1 (Exp. 1) contained a subgroup of cows both from farm A and B, while experiment 2 (Exp. 2) was conducted only on farm A. Farm A had an average 305-d mature equivalent milk yield of $11,438 \mathrm{~kg} / \mathrm{cow}$ with an average herd size of approximately 1,700 lactating Holstein cows. Farm B had an average 305-d mature equivalent milk yield of $10,533 \mathrm{~kg} /$ cow with an average herd size of approximately 1,300 lactating Holstein cows. The practices outlined in the Guide for the Care and Use of Agricultural Animals in Research and Teaching (FASS, 2010) were used for the approval of all experimental procedures as part of the local requirements. The study was approved by The University of British Columbia's Animal Care Committee (protocol A14-0290).

\section{Animals, Housing, and Management}

Cows from Exp. 1 and 2 were enrolled at the beginning of an ovulation synchronization protocol. Cows enrolled from farm A (Exp. 1 and 2) were housed in a cross-ventilated freestall barn. Milking was performed in a 72-stall rotary parlor 3 times daily, and cows were fed a TMR twice daily. Cows enrolled from farm B (subgroup of Exp. 1) were housed in a freestall barn with fans for cooling. Milking was performed in a double 24-stall side-by-side parlor 3 times daily and cows were fed TMR 3 times daily. The TMR was pushed up 3 time daily on both farms and formulated to meet or exceed the requirements of a lactating Holstein cow producing $40 \mathrm{~kg} / \mathrm{d}$ of $3.5 \%$ FCM (NRC, 2001). Water and TMR were available for ad libitum intake on both farms. Cows in Exp. 1 were assessed for BCS at enrollment ( 1 to 5 scale at 0.25 increments; Edmonson et al., 1989). Daily milk production was recorded for the cows of both experiments. 


\section{Ovulation Synchronization Protocol and Embryo Transfer}

In both experiments, cows were enrolled into an ovulation synchronization protocol based on progesterone and estradiol, as described by Pereira et al. (2015). In the case of a negative pregnancy diagnosis, cows were re-enrolled again on the same protocol. The synchronization protocol consisted of an intravaginal progesterone implant containing $1.9 \mathrm{~g}$ of progesterone (CIDR, Zoetis), a $2.0 \mathrm{mg}$ i.m. injection of estradiol benzoate (2.0 mL of Gonadiol, Zoetis), and a $100 \mu \mathrm{g}$ i.m. injection of gonadorelin diacetate $(\mathrm{GnRH} ; 2.0 \mathrm{~mL}$ of Cystorelin, Merial) on $-11 \mathrm{~d}$ relative to the end of the protocol; then, on $-4 \mathrm{~d}$ and $-2 \mathrm{~d}$ a $25 \mathrm{mg}$ i.m. injection of dinoprost tromethamine $(5.0 \mathrm{~mL}$ of Lutalyse, Zoetis) was given, and on $-2 \mathrm{~d}$ the CIDR was withdrawn and a $1.0 \mathrm{mg}$ i.m. injection of estradiol cypionate $(0.5 \mathrm{~mL}$ of estradiol cypionate, Zoetis) was administrated. Embryo transfer was performed $9 \mathrm{~d}$ after the end of the protocol and only cows that had a corpus luteum (CL) received an ET. Embryos that were produced in vivo, were obtained from super-ovulated nulliparous Holstein heifers for Exp. 1 and 2, whereas oocytes obtained for in vitro-produced (IVF) embryos used in Exp. 2 were collected through an ovum pick-up procedure in lactating cows that were selected by the herd veterinary. The superovulation synchronization protocol used for the nulliparous heifers: a second-use CIDR (i.e., previously used for $9 \mathrm{~d}$ ) and $2.0 \mathrm{mg}$ (i.m.) injection of estradiol benzoate $(2.0 \mathrm{~mL}$ of RIC-BE, Agener Uniao) were administered in the afternoon (PM) of $\mathrm{d} 0$, followed by the administration (i.m. injection) of FSH (Folltropin, Vetoquinol) once on d 4 (PM; $2.0 \mathrm{~mL})$, twice on d 5 (AM $2.0 \mathrm{~mL}$; PM $1.5 \mathrm{~mL}$ ), twice on d 6 (AM $1.5 \mathrm{~mL}$; PM $1.0 \mathrm{~mL}$ ), twice on d 7 (AM $1.0 \mathrm{~mL}$; PM $0.5 \mathrm{~mL}$ ), and once on d 8 (AM $0.5 \mathrm{~mL}$ ). Additionally, $25 \mathrm{mg}$ i.m. injections of dinoprost tromethamine were administered on $\mathrm{d} 6(\mathrm{PM})$ and $\mathrm{d} 7(\mathrm{AM})$. The CIDR was removed on d 8 (AM) and on d 9 (AM) a $4 \mathrm{mg}$ i.m. injection of gonadorelin (4 mL of Fertagyl, MSD Animal Health) was administered, AI was carried out on d $9(\mathrm{PM})$ and d 10 (AM), and on d 16 oocyte-embryo collection was performed.

All embryos used in this study were produced by commercial companies. Two companies were used, one for each farm (FAL Pioneiros, Parana, Brazil, on farm $\mathrm{A}$ and Sanches and Vieira Embryos, Parana, Brazil, on farm B), during the time of the data collection. Recipient cows received a single embryo, placed into the uterine horn ipsilateral to the CL. The embryos were transferred by an experienced veterinarian in both experiments. The embryos used in Exp. 1 were fresh in vivo-produced embryos of excellent or good and fair quality (grades 1 and 2) in the stages of morula, early blastocyst, and blastocyst according to the International Embryo Technology Society guidelines (Stringfellow and Givens, 2010). A description of the embryos used for Exp. 1 is available in Table 2. The embryos used in Exp. 2 were fresh and frozen in vivo-produced and fresh IVF. The criteria for the choice of embryos used in Exp. 2 was identical to Exp. 1; however, the information was not recorded.

Ovaries of all cows were examined by transrectal ultrasonography (5.0 MHz linear probe; Honda HS 101V, Honda) on the day of ET to check for the presence of a CL as a confirmation of ovulation. Absence of a CL was classified as an ovulation failure, and cows did not receive an embryo and were not enrolled in the present study.

Pregnancy diagnosis was carried out via ultrasonography on 29 d (Exp. 1 and 2) and 58 d (Exp. 1) after the end of the ovulation synchronization protocol. Cows were considered pregnant when a viable embryo with a heartbeat was detected. Pregnancy per ET was defined as the proportion of cows that received an embryo and were pregnant on $29 \mathrm{~d}$ (Exp. 1 and 2) and 58 d (Exp. 1) after the end of the protocol. Pregnancy loss was defined as the proportion of pregnant cows on $29 \mathrm{~d}$ after the end of the synchronization protocol that were found nonpregnant on d 58 (Exp. 1). Technicians were unaware of estrous expression of the animals when pregnancy diagnosis was performed. The technicians that were conducting the ET (in vivo, in vitro, and by the quality of the embryo) were also unaware of the information regarding estrous expression.

\section{Detection of Estrus-Automated Activity Monitor and Tail Chalk}

To assess the occurrence of estrus in Exp. 1 (farm A and B), tail chalk was applied on the tail head of the cows on the day of CIDR removal $(-2 \mathrm{~d})$ and at 0 $\mathrm{d}$ (end of the ovulation synchronization protocol) and cows were later evaluated for chalk presence or removal by an experienced researcher. Cows were then classified as having no estrus if all the chalk was still visible and were considered to have shown estrus if $<50 \%$ of the chalk was still visible.

In Exp. 2, AAM were used to determine both the occurrence of estrus as well as the intensity of estrous expression. Cows were monitored continuously with a leg-mounted pedometer (AfiPedometer Plus Tag; AfiMilk) attached to the right back limb of each cow on the day of their first calving. The steps per hour were recorded in 2 -h blocks and retrieved by a computer 
system. Relative increase (RI) in steps/h was calculated by determining the change in steps on $-1 \mathrm{~d}$ and $0 \mathrm{~d}$, relative to the end of the ovulation synchronization protocol, in comparison to a baseline calculated for each cow. Baseline steps per hour represented the average steps per hour from the $7 \mathrm{~d}(-11$ to $-4 \mathrm{~d})$ before the end of the timed ET protocol. The following formula was used: [(steps/h at estrus - steps/h at baseline $) /$ steps $/ \mathrm{h}$ at baseline] $\times 100]$. The steps per hour at estrus was defined as the greatest number of steps on $-1 \mathrm{~d}$ or $0 \mathrm{~d}$ relative to timed ET. Cows were only considered to be in estrus if the RI on $-1 \mathrm{~d}$ or 0 $\mathrm{d}$ exceeded $100 \%$ at the end of the timed ET protocol.

\section{Statistical Analyses}

In Exp. 1 and 2, power calculations were carried out to determine a minimum sample size $(\mathrm{n}=250$ per group $)$ required to identify a difference of $15 \%$ (20\% vs. $35 \%$ ) in pregnancy per ET, between cows expressing estrus or not (Exp. 1) and between weak or strong intensity of estrous expression (Exp. 2) at the end of the timed ET protocol, with $95 \%$ confidence and $80 \%$ power. Proportion of the variance of the exposure explained by the confounders used was 0.5. The number of individuals sampled per cluster was considered as 3 and the intraclass correlation coefficient between individuals in the cluster was considered 0.3. Power calculations were carried out following procedures outlined by Dohoo et al. (2009).

Distributions and normality tests were obtained using the Univariate procedure in the SAS software, version 9.4 (SAS Institute Inc.). Class variables used for the analyses are described below. Parity was divided into primiparous (cows in first lactation) and multiparous (cows in second lactation or greater) for both experiments. For Exp. 1, BCS was categorized as low $(<2.75)$, moderate $(2.75-3.00)$, and high $(\geq 3.25)$ using the 33rd percentiles. Milk production was classified into quartiles of each experiment, Exp. 1: first quartile: $\leq 31.9$ $\mathrm{kg} / \mathrm{d}$; second quartile: 32.0 to $39.2 \mathrm{~kg} / \mathrm{d}$; third quartile: 39.3 to $46.1 \mathrm{~kg} / \mathrm{d}$; and fourth quartile: $\geq 46.2 \mathrm{~kg} / \mathrm{d}$; and for Exp. 2: first quartile: $\leq 28.8 \mathrm{~kg} / \mathrm{d}$; second quartile: 28.9 to $37.8 \mathrm{~kg} / \mathrm{d}$; third quartile: 37.9 to $45.8 \mathrm{~kg} / \mathrm{d}$; and fourth quartile: $\geq 45.9 \mathrm{~kg} / \mathrm{d}$. Physical activity of estrus episodes in Exp. 2 was categorized as no estrus $(<100 \% \mathrm{RI})$, weak intensity (100-299\% RI), and strong intensity ( $\geq 300 \%$ RI), as described by Madureira et al. (2019), where $100 \%$ was used as the criteria for estrus and $300 \%$ was used to split estrous expression data by the median of cows that demonstrated estrus. Activity data from 5 events were missing on Exp. 2.
Pregnancy per ET was used as a binomial dependent variable and was tested for the effects of parity, BCS, DIM, milk production, embryo developmental stage and quality, and occurrence (Exp. 1) and intensity (Exp. 2) of estrous expression using ANOVA, with ET event as the experimental unit and cow as a random effect using linear mixed regression models (GLIMMIX) in SAS. All multivariable models were constructed using the variables as described above and manual backward stepwise elimination was used, where variables were retained with $P \leq 0.15$. Differences with $P \leq 0.05$ were considered significant and those between $0.05>$ $P \leq 0.10$ were designated as a tendency with results reported as least squares means where applicable. Final models are described in Table 1.

\section{RESULTS}

\section{Animals, Number of Events, and Farm}

In Exp. 1, a total of 1,401 ET events from 1,045 cows were recorded (farm $\mathrm{A}, \mathrm{n}=664$; and farm $\mathrm{B}, \mathrm{n}$ $=381$ ). The descriptive data for each farm in Exp. 1 is described in Table 2. A total of 1,147 ET events from 657 cows were recorded for Exp. 2 with an average milk production during data collection of $37.8 \pm 12.1$ $\mathrm{kg} / \mathrm{d}$ averaging $226.1 \pm 139.4$ DIM. In Exp. 2, 24.9\% and $75.1 \%$ of cows enrolled were primiparous and multiparous, respectively. Sixty percent $(689 / 1,147), 22.8 \%$ $(261 / 1,147)$, and $17.2 \%(197 / 1,147)$ of the embryos transferred were from IVF, in vivo frozen, and in vivo fresh, respectively.

\section{Estrous Expression at the End of the Timed ET Protocol}

A total of $65.2 \%(914 / 1,401)$ and $89.2 \%(1,019 / 1,142)$ of cows from Exp. 1 and 2, respectively, displayed estrus at the end of the ovulation synchronization protocol. The mean and the median RI at estrus, in Exp. 2, was $281.3 \pm 180.9 \%$ and $296.8 \%$, respectively. Parity influenced the expression of estrus, as multiparous cows were more likely to be classified as in estrus using tail chalk than primiparous $[67.4 \%(652 / 968)$ vs. $60.5 \%$ (262/433); $P=0.01$, respectively], in Exp. 1. In Exp. 2, multiparous cows expressed lesser RI at the end of the timed ET protocol $(P<0.01$; Table 3$)$ when compared with primiparous cows. The proportion of cows showing no estrous expression, weak, and strong intensity estrous expression, by parity and milk production, is shown in Table 3. There was an interaction between parity and the intensity of estrous expression 
Table 1. Final mixed multivariable models, with embryo transfer event as the experimental unit and cow within farm as the random effect, for both experiment 1 and experiment 2

\begin{tabular}{|c|c|c|}
\hline Outcome & Independent variable & $P$-value \\
\hline \multicolumn{3}{|l|}{ Experiment 1} \\
\hline \multirow[t]{7}{*}{ Pregnancy at $29 \mathrm{~d}$} & Occurrence of estrus ${ }^{1}$ & $<0.0001$ \\
\hline & Embryo quality $^{2}$ & 0.03 \\
\hline & Stage of embryo development ${ }^{3}$ & $<0.001$ \\
\hline & Milk production ${ }^{4}$ & 0.06 \\
\hline & Farm & 0.09 \\
\hline & Parity & 0.07 \\
\hline & Occurrence of estrus $\times$ stage of embryo development & $<0.01$ \\
\hline \multirow[t]{3}{*}{ Pregnancy at $58 \mathrm{~d}$} & Embryo quality & 0.05 \\
\hline & Stage of embryo development & $<0.001$ \\
\hline & Occurrence of estrus $\times$ stage of embryo development & $<0.05$ \\
\hline Pregnancy loss & Parity $^{5}$ & 0.08 \\
\hline \multicolumn{3}{|l|}{ Experiment 2} \\
\hline \multirow{4}{*}{ Pregnancy at $29 \mathrm{~d}$} & Intensity of estrus ${ }^{6}$ & $<0.0001$ \\
\hline & Intensity of estrus $\times$ parity & $<0.0001$ \\
\hline & Embryo transfer type & 0.05 \\
\hline & Milk production & 0.01 \\
\hline \multirow[t]{2}{*}{ Intensity of estrus } & Parity & $<0.001$ \\
\hline & Milk production & $<0.05$ \\
\hline \multicolumn{3}{|c|}{$\begin{array}{l}{ }^{1} \text { Occurrence of estrus: evaluated for chalk presence or removal (no estrus: } 100 \% \text { of chalk remaining; estrus: } \\
<50 \% \text { of chalk remaining). }\end{array}$} \\
\hline \multicolumn{3}{|c|}{${ }^{2}$ Embryo quality: embryos were classified as excellent or good and fair quality (grade 1 and 2). } \\
\hline \multicolumn{3}{|c|}{${ }^{3}$ Stage of embryo development: embryos were classified as morula, blastocyst, and early blastocyst. } \\
\hline \multicolumn{3}{|c|}{$\begin{array}{l}{ }^{4} \text { Milk production: milk production was recorded daily, and it was categorized into quartiles in both experi- } \\
\text { ments. }\end{array}$} \\
\hline \multicolumn{3}{|c|}{${ }^{5}$ Parity: parity was categorized into primiparous and multiparous in both experiments. } \\
\hline \multicolumn{3}{|c|}{$\begin{array}{l}{ }^{6} \text { Estrous expression was quantified using the relative increase at estrus, and an estrus episode on was classified } \\
\text { as no estrus }[<100 \% \text { relative increase in activity (RI)], weak intensity }(100-299 \% \mathrm{RI}) \text {, and strong intensity } \\
(\geq 300 \% \text { RI). }\end{array}$} \\
\hline \multicolumn{3}{|c|}{$\begin{array}{l}{ }^{7} \text { Embryo transfer type: the embryos used in experiment } 1 \text { were fresh and frozen in vivo produced; in experiment } \\
2 \text { embryos were fresh and frozen in vivo produced and fresh in vitro produced. }\end{array}$} \\
\hline
\end{tabular}

on pregnancy per ET $(P<0.01)$, as shown in Figure 1 . Milk production did not affect the proportion of cows expressing estrus when milk production was classified

Table 2. Descriptive data considering farm A $[900$ embryo transfer (ET) events] and farm B (501 ET events) utilizing fresh and frozen in vivo-produced embryos of experiment 1

\begin{tabular}{lcc}
\hline Variable & Farm A & Farm B \\
\hline Number of events & 900 & 501 \\
Milk production (mean \pm SD; kg/d) & $37.1 \pm 11.6$ & $41.4 \pm 8.4$ \\
DIM (mean \pm SD; d) & $212.1 \pm 87.6$ & $150.4 \pm 93.4$ \\
Parity [\%, (n)] & $40.6(365)$ & $13.6(68)$ \\
$\quad$ Primiparous & $59.4(535)$ & $86.4(433)$ \\
$\quad$ Multiparous & & \\
Embryo development stage [\%, (n)] & $34.0(306)$ & $29.1(146)$ \\
$\quad$ Early blastocyst & $11.8(106)$ & $13.2(66)$ \\
$\quad$ Blastocyst & $54.2(488)$ & $57.7(289)$ \\
$\quad$ Morula & $76.4(688)$ & $75.8(380)$ \\
Embryo quality [\%, (n)] & $23.6(212)$ & $24.2(121)$ \\
$\quad$ Excellent or good & $39.5(356)$ & $35.1(176)$ \\
$\quad$ Fair & $32.2(290)$ & $26.2(131)$ \\
Pregnancy per ET ${ }^{1}$ at 29 d [\%, (n)] &
\end{tabular}

${ }^{1}$ Pregnancy per ET: pregnancy detection was carried out via ultrasonography on 29 and $58 \mathrm{~d}$ after the end of the timed ET protocol, and cows were considered pregnant when a heartbeat of the embryo was present. into quartiles in Exp. 1 first quartile: $60.9 \%$ (208/330); second quartile: $67.5 \%$ (221/323); third quartile: $65.6 \%$ (216/325); and fourth quartile: $61.4 \%$ (209/327), $P=$ 0.21]. In Exp. 2, there was a negative correlation between milk production and RI $(\mathrm{r}=-0.15 ; P<0.01)$. Greater milk production was associated with lesser RI (Table 3) when milk production was classified into quartiles. There was a greater proportion of cows with high BCS which displayed estrus compared with cows having lower or moderate BCS $[76.7 \%(195 / 254)$ vs. $67.4 \%(122 / 181)$ vs. $64.8 \%(155 / 239) ; P<0.05$; respectively] in Exp. 1.

\section{Pregnancy Per ET and Pregnancy Loss}

Pregnancy per ET was influenced by the occurrence and intensity of estrous expression, embryo transfer type, milk production, but not by parity, BCS, and DIM (Table 1). In Exp. 1, cows that expressed estrus had greater pregnancy per ET compared with cows that did not display estrus $[41.0 \pm 2.3(381 / 914)$ vs. $31.5 \pm 2.9(151 / 487) ; P<0.01$, respectively]. Similarly, in Exp. 2, cows that had greater estrous expression at the end of the ovulation synchronization protocol, as 
Table 3. Relative increase in activity at the end of the synchronization protocol and pregnancy per embryo transfer (ET) considering parity and milk production of experiment 2

\begin{tabular}{|c|c|c|c|c|c|}
\hline Variable & $\begin{array}{c}\text { Relative increase }^{1} \\
{[\text { mean } \% \pm \operatorname{SEM}(\mathrm{n})]}\end{array}$ & $\begin{array}{c}\text { Pregnancy } / \mathrm{ET}^{2} \\
{[\text { mean } \%, \pm \text { SEM }(\mathrm{n} / \mathrm{n})]}\end{array}$ & \multicolumn{3}{|c|}{ Classification of estrous expression ${ }^{3}[\%,(\mathrm{n} / \mathrm{n})]$} \\
\hline Multiparous & $275.1 \pm 6.8^{\mathrm{b}}(861)$ & $31.1 \pm 1.7(265 / 861)$ & $19.5(168 / 861)$ & $33.2^{\mathrm{b}}(286 / 861)$ & $47.3^{\mathrm{b}}(407 / 861)$ \\
\hline \multicolumn{6}{|c|}{ Milk production $(\mathrm{kg} / \mathrm{d})$} \\
\hline$\leq 28.8$ & $324.7 \pm 10.9^{\mathrm{a}}(287)$ & $37.5 \pm 3.2^{\mathrm{a}}(99 / 287)$ & $14.5^{\mathrm{a}}(55 / 379)$ & $26.4^{\mathrm{a}}(100 / 379)$ & $59.1^{\mathrm{a}}(224 / 379)$ \\
\hline$\geq 45.9$ & $243.2 \pm 11.3^{\mathrm{b}}(279)$ & $25.8 \pm 3.0^{\mathrm{b}}(69 / 279)$ & $20.8^{\mathrm{b}, \mathrm{y}}(58 / 279)$ & $46.9^{\mathrm{c}}(131 / 279)$ & $32.3^{\mathrm{c}}(90 / 279)$ \\
\hline
\end{tabular}

${ }^{\mathrm{a}-\mathrm{c}}$ Within a column, different superscripts indicate differences between variables $(P<0.05)$.

${ }^{\mathrm{x}, \mathrm{y}}$ Within a column, different superscripts indicate a tendency between variables $(P=0.10)$.

${ }^{1}$ Relative increase in activity was calculated as the percentage increase in activity at estrus in relation to each cow's own basal activity (rolling average of the $7 \mathrm{~d}$ before estrus).

${ }^{2}$ Pregnancy/ET: pregnancy detection was carried out via ultrasonography on $29 \mathrm{~d}$ after the end of the timed ET protocol, and cows were considered pregnant when a heartbeat of the embryo was present.

${ }^{3}$ Classification of estrous expression: no estrus $=<100 \%$ relative increase (RI) in activity detected by the automated activity monitor (AAM); weak intensity $=100-299 \%$ RI in activity detected by the AAM; strong intensity $=\geq 300 \%$ RI in activity detected by AAM.

determined using the AAM, had greater pregnancy per ET $(P<0.01$; Table 3). In Exp. 1, there was no effect of embryo transfer type (in vivo frozen or fresh) on pregnancy per ET $(P=0.42)$. However, in Exp. 2, cows that received an in vivo embryo, either fresh or frozen, had greater pregnancy per ET compared with cows that received an IVF embryo $(P<0.01$; Table 4$)$. Pregnancy per ET was affected by the stage of embryo development in Exp. 1, as cows receiving embryos in the early blastocyst and blastocyst stage had greater fertility on $29 \mathrm{~d}$ and $58 \mathrm{~d}$ after the end of timed ET protocol when compared with cows receiving embryos in the morula stage (Table 5). There was, however, an interaction between the occurrence of estrus (estrus and no estrus) and embryo developmental stage of the transferred embryo on pregnancy per ET at $29(P<$ $0.01)$ and $58(P<0.05)$ d postsynchronization (Figure $2)$. Cows that received a morula or early blastocyst

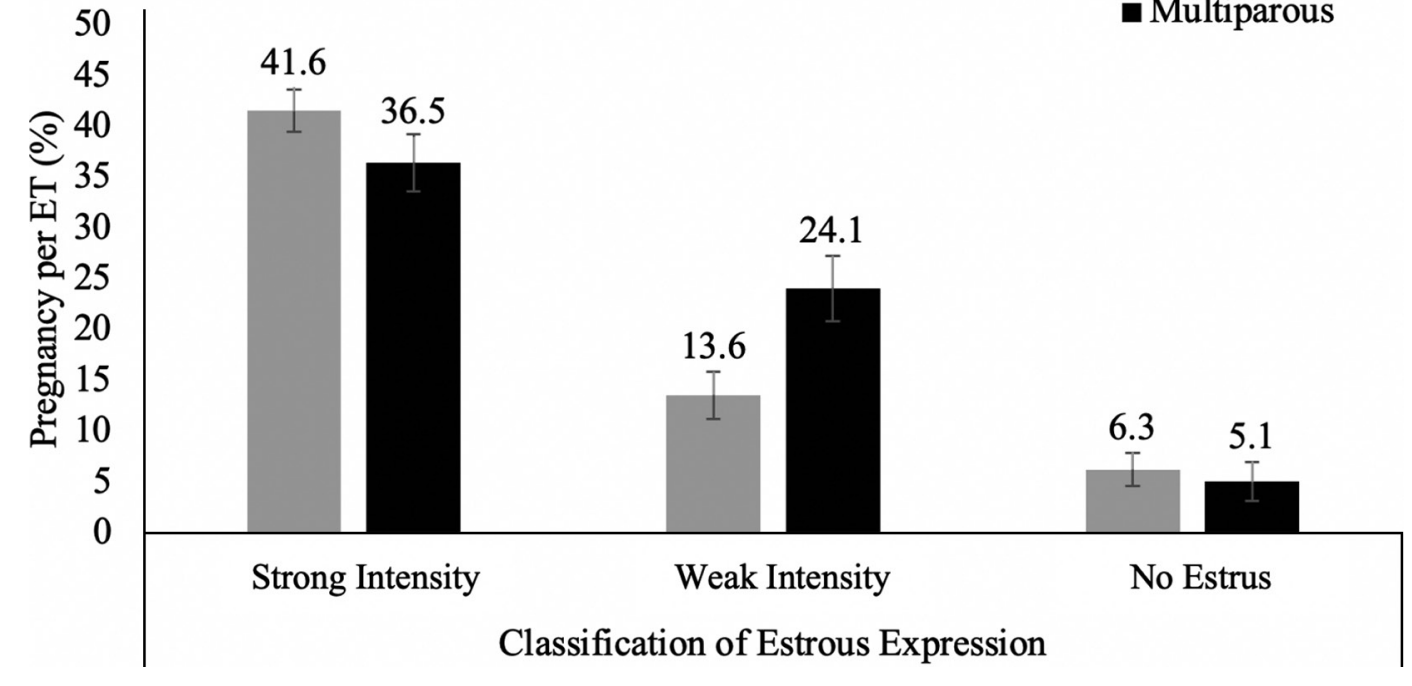

Primiparous

- Multiparous

Figure 1. Pregnancy per embryo transfer (ET) according to parity (primiparous and multiparous) and the intensity of estrous expression (strong intensity, weak intensity, and no estrus) in experiment 2 . The mean $\% \pm$ SEM (n/n) for primiparous and multiparous, respectively, was $41.6 \pm 2.1 \%(68 / 166)$ vs. $36.5 \pm 2.8 \%(151 / 407), P=0.37$, for strong intensity; $13.6 \pm 2.3 \%(9 / 68)$ vs. $24.1 \pm 3.2 \%(72 / 286), P=0.03$, for weak intensity; and $6.3 \pm 1.6 \%(4 / 52)$ vs. $5.1 \pm 1.9 \%(6 / 168), P=0.41$, for no estrus. An interaction was observed between parity and the intensity of estrous expression on pregnancy per ET $(P<0.01)$. 
Table 4. Pregnancy per embryo transfer (ET) according to the classification of the intensity of estrous expression detected by an automated activity monitor (AAM) and by the embryo transfer type of experiment 2

\begin{tabular}{ll}
\hline Variable & $\begin{array}{c}\text { Pregnancy/ET } \\
{[\text { mean } \% \pm \mathrm{SEM}(\mathrm{n} / \mathrm{n})]}\end{array}$ \\
\hline $\mathrm{AAM}^{2}$ & \\
$\quad$ Strong intensity & $41.3 \pm 2.2^{\mathrm{a}}(213 / 571)$ \\
Weak intensity & $32.7 \pm 2.7^{\mathrm{b}}(115 / 353)$ \\
$\quad$ No estrus & $11.3 \pm 3.5^{\mathrm{c}}(26 / 218)$ \\
ET type & $35.2 \pm 2.9^{\mathrm{a}}(93 / 261)$ \\
In vivo fresh & $35.6 \pm 3.5^{\mathrm{a}}(65 / 197)$ \\
In vivo frozen & $28.1 \pm 1.9^{\mathrm{b}}(197 / 689)$ \\
\hline In vitro fertilization &
\end{tabular}

${ }^{\mathrm{a}-\mathrm{c}}$ Within a column, different superscripts indicate differences between variables $(P<0.05)$.

${ }^{1}$ Pregnancy/ET: pregnancy detection was carried out via ultrasonography on $29 \mathrm{~d}$ after the end of the timed ET protocol, and cows were considered pregnant when a heartbeat of the embryo was present.

${ }^{2}$ Estrous expression was quantified using the relative increase at estrus, and an estrus episode on was classified as no estrus $[<100 \%$ relative increase in activity (RI)], weak intensity (100-299\% RI), and strong intensity $(\geq 300 \% \mathrm{RI})$.

had greater pregnancy per ET when transferred into cows that displayed estrus compared with cows that did not display estrus when pregnancy was assessed at $29 \mathrm{~d}$ postsynchronization. There was no interaction between estrous expression (weak and strong intensity) and stage of embryo development $(P=0.44)$ or embryo quality $(P=0.67)$ on pregnancy per ET in Exp. 1 .

Milk production had a tendency to affect pregnancy per ET in Exp. $1(P=0.06)$. Similarly, milk production was associated with pregnancy per ET $(P=0.01)$ in Exp. 2 (Table 3), independent of ET type $(P=0.22)$. Pregnancy per ET tended to be influenced by parity $(P=0.07)$ in Exp. 1 but not in Exp. $2(P=0.78)$. There was no interaction between parity and embryo transfer type on pregnancy per ET. Days in milk did not influence pregnancy per ET in either experiment.
Pregnancy loss was not influenced by the quality of the embryo $(P=0.61)$, by ET type $(P=0.46)$ or stage of the embryo $(P=0.19)$. Also, pregnancy loss was not associated with milk production $(P=0.99)$, BCS $(P=$ 0.44 ), or the occurrence of estrus detected by tail chalk $(P=0.26)$. Pregnancy loss was only evaluated in Exp. 1. Pregnancy loss tended to be greater in primiparous compared with multiparous cows $[20.7 \pm 2.7 \%(39 / 187)$ vs. $14.7 \pm 2.2(51 / 345) \%, P=0.08$; respectively]. There was no farm effect on pregnancy loss $(P=0.36)$ in Exp. 1.

\section{DISCUSSION}

The aim of this study was to determine the association between the occurrence and intensity of estrus events and fertility in recipient dairy cows subjected to ET. The occurrence (Exp. 1 and 2) and intensity of estrus events (Exp. 2) influenced pregnancy per ET. Pregnancy per ET was affected by the stage of embryo development, but not embryo quality, as demonstrated by greater fertility observed in cows receiving embryos in the early blastocyst and blastocyst stage compared with cows receiving embryos in the morula stage. Furthermore, cows that displayed estrus and received an embryo in a morula or early blastocyst had greater pregnancy per ET than cows that did not display estrus. Previous studies have shown that expression of estrus detected by a breeding indicator (Pereira et al., 2016) or the intensity of estrous expression at spontaneous estrus or timed AI, measured using AAM, were associated with improvements in fertility (Madureira et al., 2015, 2019), and lesser ovulation failure (Burnett et al., 2018) and pregnancy loss (Pereira et al., 2016). There is a knowledge gap on the literature regarding the effects of occurrence and intensity of estrous expression on the success of ET and its relationship with embryo quality.

Table 5. Pregnancy per embryo transfer (ET) at 29 and 58 d postsynchronization protocol, according to the stage of embryo development and embryo quality of experiment 1

\begin{tabular}{|c|c|c|}
\hline Variable & $\begin{array}{l}\text { Pregnancy per ET } \mathrm{ET}^{1} \text { at } 29 \mathrm{~d} \\
{[\text { mean } \% \pm \operatorname{SEM}(\mathrm{n} / \mathrm{n})]}\end{array}$ & $\begin{array}{l}\text { Pregnancy per ET at } 58 \mathrm{~d} \\
{[\text { mean } \% \pm \operatorname{SEM}(\mathrm{n} / \mathrm{n})]}\end{array}$ \\
\hline \multicolumn{3}{|c|}{ Embryo development stage } \\
\hline Early blastocyst & $42.1 \pm 2.4^{\mathrm{a}}(184 / 452)$ & $28.4 \pm 2.6^{\mathrm{a}, \mathrm{x}}(148 / 452)$ \\
\hline Blastocyst & $46.5 \pm 3.8^{\mathrm{a}}(79 / 172)$ & $31.3 \pm 4.0^{\mathrm{a}}(63 / 172)$ \\
\hline Morula & $35.3 \pm 1.8^{\mathrm{b}}(269 / 777)$ & $23.4 \pm 1.9^{\mathrm{b}, \mathrm{y}}(210 / 777)$ \\
\hline \multicolumn{3}{|l|}{ Embryo quality } \\
\hline Excellent and good & $39.2 \pm 1.9^{\mathrm{a}}(430 / 1,068)$ & $31.6 \pm 1.9^{\mathrm{a}}(344 / 261)$ \\
\hline Fair & $32.5 \pm 3.3^{\mathrm{b}}(102 / 333)$ & $23.8 \pm 3.1^{\mathrm{b}}(65 / 197)$ \\
\hline
\end{tabular}




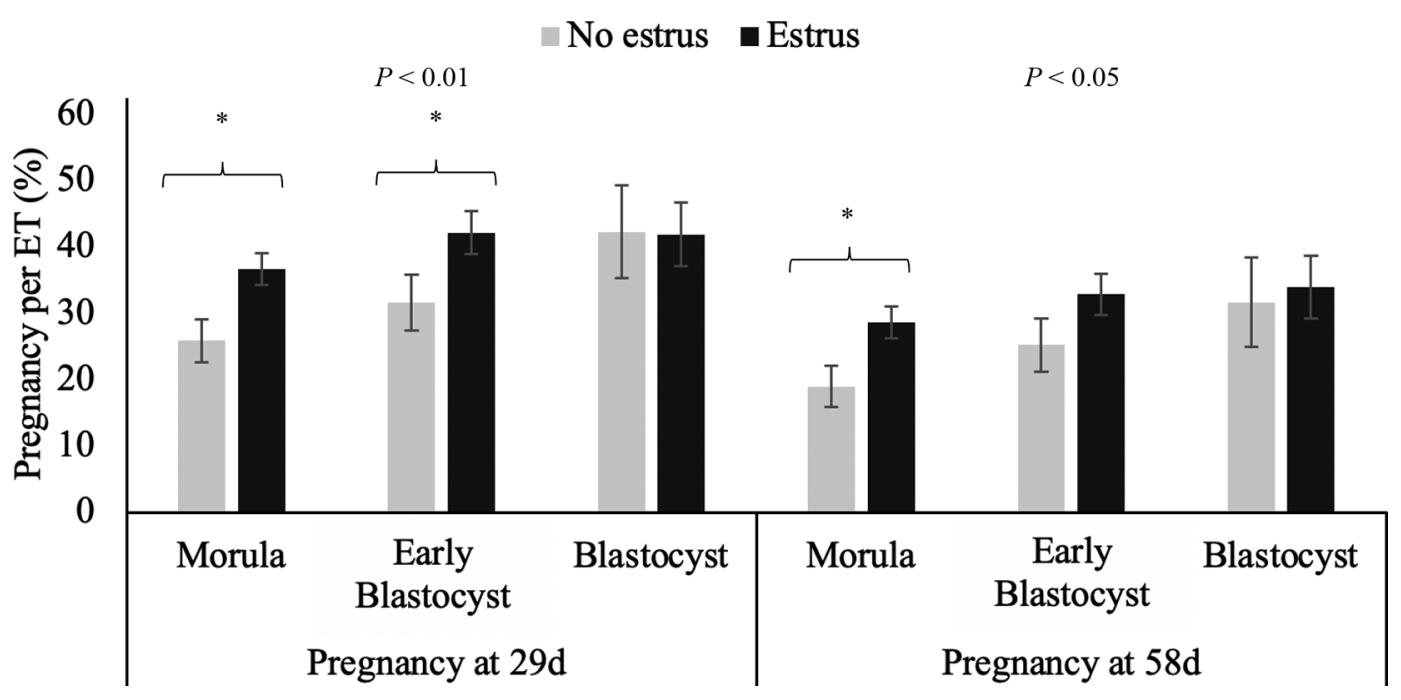

Figure 2. Pregnancy per embryo transfer (ET; mean $\% \pm$ SEM) according to the stage of embryo development and the occurrence of estrus (estrus) or not (no estrus), in experiment 1. Pregnancy examination was performed at 29 and $58 \mathrm{~d}$ after the end of the timed ET. An interaction was observed between the occurrence of estrus (estrus and no estrus) and embryo developmental stage of the transferred embryo on pregnancy per ET. Asterisks indicate differences between bars $(P<0.05)$.

In cattle, P4 and estradiol (E2) are the main hormones that control the estrous cycle and induce behavioral estrus. Progesterone is associated with estrous expression, embryonic development (Rivera et al., 2011), and fertility of dairy cattle (Bisinotto et al., 2010). Pereira et al. (2016) showed that cows that did not express estrus at the end of a timed AI protocol were more likely to have greater concentration of $\mathrm{P} 4$ at estrus when compared with cows that expressed estrus. Additionally, P4 concentration during proestrus may be associated with estrous expression and intensity, as P4 primes the hypothalamus, making it more responsive to E2 and the occurrence of estrous expression (Woelders et al., 2014). A positive relationship between the concentration of E2 and the intensity of estrus behavior has been shown in several studies (Britt et al., 1986; Lyimo et al., 2000; Lopez et al., 2004), although no relationship was found between E2 concentrations at estrus and estrous expression measured using an AAM (Madureira et al., 2015). Nevertheless, there is evidence that increased concentrations of $\mathrm{E} 2$ at the time of estrus has a positive effect on fertility (Buhi, 2002; Jinks et al., 2013). A study by Jinks et al. (2013) reported that cows that had greater concentrations of E2 at estrus had a greater number of fertilized embryos, greater concentrations of $\mathrm{P} 4$ post-AI and greater conception rates than cows with lower E2 concentrations. Progesterone, E2, or both may be the key to these results. However, in the current study we did not measure these steroidal hormones.

Cows that received an in vivo embryo, either frozen or fresh, had greater pregnancy per ET compared with cows that received an IVF embryo. Previous studies have shown slightly lesser pregnancy per ET resulting from embryo transfers of in vitro compared with in vivoproduced embryos (Wright and Ellington, 1995; Hasler, 2001). The processes of IVF results in darker and lower density cytoplasms (Pollard and Leibo, 1994), swollen blastomeres (Van Soom et al., 1992), more fragile zona pellucida (Duby et al., 1997), differences in intercellular communication (Boni et al., 1999), a higher incidence of chromosomal abnormalities (Viuff et al., 1999; Slimane et al., 2000), slower growth rates, and higher thermal sensitivity (Leibo and Loskutoff, 1993). These factors may be responsible for lower fertility for in vitro-produced embryos.

Pregnancy per ET was also affected by the stage of embryo development. Cows receiving embryos in the early blastocyst and blastocyst stage had greater fertility compared with embryos of morula stage. These results support conclusions from previous studies (Ferraz et al., 2016; Erdem et al., 2020). However, previous studies have reported no effect of embryo stage on the success of ET (Spell et al., 2001; Demetrio et al., 2007). In the current study, an interaction between estrous expression and developmental stage of the embryo was observed. Cows receiving less advanced embryos (morula and early blastocyst) benefited from the occurrence of estrus, perhaps because of a more receptive uterine environment. More advanced embryos (blastocyst) might be mature enough to maintain pregnancy even in less ideal situations. Previous research has reported that cows with greater estrous expression have greater concentration of P4 post-AI (Madureira et al., 2019). 
The ability of the embryo to produce interferon tau has been correlated with circulating $\mathrm{P} 4$ concentrations during the luteal phase. Poor P4 secretion during the luteal phase may result in the development of poor embryos unable to produce, or producing lower amounts of interferon tau (Mann et al., 2006), thus decreasing its ability to maintain pregnancy (Bauersachs et al., 2012).

In this study, a total of $89.2 \%$ of cows were detected in estrus by the AAM and a total of $65.2 \%$ cows were detected by the tail chalk method. The detection rates for cows that received tail chalk were much lower than the detection rates for the cows that were fitted with an AAM. Standing to be mounted has been the gold standard for detection of estrus (Roelofs et al., 2010). However, this behavior in lactating dairy cows is reduced (Rivera et al., 2010). The decrease in this behavior has been associated with high milk production (Lopez et al., 2004), freestall systems and the size of the herd (Britt et al., 1986; Palmer et al., 2012; Stevenson and Britt, 2017). Estrus behavior is induced once E2 concentrations reach an individual threshold. The minimum concentration of circulating E2 or the duration of exposure to E2 necessary to trigger estrus is likely dependent on several factors that are probably not uniform among cows, perhaps leading to variations in sexual behaviors displayed during estrus and having a more negative effect on mounting and standing to be mounted than on secondary signs of estrus.

Multiparous cows in this study displayed lesser intensity of estrous expression at the end of a timed ET protocol compared with primiparous. In a study by López-Gatius et al. (2005), walking activity during estrus decreased by $21.4 \%$ for each increase in parity number, but some other studies have found that walking activity was not associated with parity (Arney et al., 1994; Løvendahl and Chagunda, 2010). Interestingly, in Exp. 1 multiparous cows were more likely to display estrus than primiparous cows. However, it is noteworthy that the estrus detection in Exp. 1 was by tail chalk, a tool characterized by detection of standing estrus in contrast to walking behavior. A shorter and less intense estrus has also been reported for primiparous cows when data were collected via visual scoring (Van Vliet and Van Eerdenburg, 1996). Demonstrating the vast differences in physical activity, Roelofs et al. (2005) observed that mounting occurred in $90 \%$ of estrus events, whereas standing to be mounted occurred in only $56 \%$ of estrous events; however, no effects of parity were found on standing to be mounted. The difference in methods used to evaluate the occurrence of estrus, by measuring different behaviors, may explain the different results for parity in Exp. 1 and 2.
There was no correlation between milk production and the occurrence and intensity of estrus detected by AAM. However, when data were divided in quartiles, animals in the highest quartile had lesser estrous expression (Exp. 2). The association between milk production and the intensity of estrus found in Exp. 2 is consistent with other studies (Lopez et al., 2004; Rivera et al., 2010; Madureira et al., 2015). This relationship is often explained by the elevated rate of metabolic clearance of steroidal hormones in animals with high energy intake and expenditure (Vasconcelos et al., 2003). Reduced levels of circulating reproductive hormones may lead to compromised reproductive processes, including higher multiple ovulation rates and more luteal tissue in spite of the decreased hormone present in the bloodstream (Wiltbank et al., 2006).

One limitation of our work is that the study conducted was an observational trial rather than randomized controlled experiment. This study required a large number of embryo transfers to conclude fertility outcomes, whereas with a randomized controlled experiment smaller sample sizes may have been able to be used. Another limitation of this study is that due to the experimental design we are not able to conclude which stage of embryo development estrous expression is affecting the most. For example, we are not able to determine if estrous expression is more beneficial for oocyte quality before ovulation, fertilization postovulation, or embryo development, due to only having estrous expression data for the recipients and not from the donors. However, one strength of this study was that 2 different populations were analyzed, from 2 farms in different locations using cows with varying characteristics (BCS, DIM, parity, and so on); nonetheless, we consistently found that estrous expression was associated with increase in pregnancy per ET and thus we expect that our results are generalized, and it can be applicable to other populations.

\section{CONCLUSIONS}

In conclusion, the occurrence and the intensity of estrous expression at the end of an ovulation synchronization protocol improved pregnancy per ET. Pregnancy per ET was affected by the stage of embryo development, as cows receiving embryos in the blastocyst and early blastocyst stage had greater fertility compared with cows receiving embryos in the morula stage. Cows that displayed estrus and received an embryo in a morula or early blastocyst had greater pregnancy per ET than cows that did not display estrus. These results provide evidence that the occurrence and intensity of estrous expression can predict fertility in lactating 
dairy cows and could be used as a marker to assist in the decision making in reproductive management.

\section{ACKNOWLEDGMENTS}

This study was supported by a contribution from the Dairy Research Cluster Initiative II (Dairy Farmers of Canada, Agriculture and Agri-Food Canada, the Canadian Dairy Network, and the Canadian Dairy Commission; Ottawa, Canada). Partial funding was also provided by the Natural Sciences and Engineering Research Council, Discovery Grant (Ottawa, Canada). This study was a part of the Resilient Dairy Genome Project (RDGP). The authors gratefully acknowledge the funding and support from the Resilient Dairy Genome Project including Genome Canada, Genome Alberta, Genome BC. The authors are grateful to Fazenda Colorado (Araras, Brazil) and Fazenda Sekita (São Gotardo, Minas Gerais, Brazil) and their farm personnel for contributing with this research project as well as students, interns and operational support from Conapec Jr., São Paulo State University, Botucatu, Brazil. The authors are also grateful for the collaboration with Sérgio Soriano (Fazenda Colorado, Araras, Brazil), Alex Sica, Matheus Baylão, and Flávio Aragon Lima (Clinica Fal Pioneiros). The authors have not stated any conflicts of interest.

\section{REFERENCES}

Al-Katanani, Y. M., M. Drost, R. L. Monson, J. J. Rutledge, C. E. Krininger, J. Block, W. W. Thatcher, and P. J. Hansen. 2002. Pregnancy rates following timed embryo transfer with fresh or vitrified in vitro produced embryos in lactating dairy cows under heat stress conditions. Theriogenology 58:171-182. https://doi.org/10 .1016/S0093-691X(02)00916-0.

Arney, D. R., S. E. Kitwood, and C. J. C. Phillips. 1994. The increase in activity during oestrus in dairy cows. Appl. Anim. Behav. Sci. 40:211-218. https://doi.org/10.1016/0168-1591(94)90062-0.

Bauersachs, S., S. E. Ulbrich, H.-D. Reichenbach, M. Reichenbach, M. Büttner, H. H. Meyer, T. E. Spencer, M. Minten, G. Sax, G. Winter, and E. Wolf. 2012. Comparison of the effects of early pregnancy with human interferon, alpha 2 (IFNA2), on gene expression in bovine endometrium. Biol. Reprod. 86:46. https://doi.org/10 .1095/biolreprod.111.094771.

Bisinotto, R. S., E. S. Ribeiro, L. T. Martins, R. S. Marsola, L. F. Greco, M. G. Favoreto, C. A. Risco, W. W. Thatcher, and J. E. P. Santos. 2010. Effect of interval between induction of ovulation and artificial insemination (AI) and supplemental progesterone for resynchronization on fertility of dairy cows subjected to a 5-d timed AI program. J. Dairy Sci. 93:5798-5808. https://doi.org/10.3168/ jds.2010-3516.

Boni, R., E. Tosti, S. Roviello, and B. Dale. 1999. Intercellular communication in in vivo- and in vitro-produced bovine embryos. Biol. Reprod. 61:1050-1055. https://doi.org/10.1095/biolreprod61.4 .1050 .

Britt, J. H., R. G. Scott, J. D. Armstrong, and M. D. Whitacre. 1986. Determinants of estrous behavior in lactating Holstein cows. J. Dairy Sci. 69:2195-2202. https://doi.org/10.3168/jds.S0022 -0302(86)80653-1.
Buhi, W. C. 2002. Characterization and biological roles of oviductspecific, oestrogen-dependent glycoprotein. Reproduction 123:355362. https://doi.org/10.1530/rep.0.1230355.

Burnett, T. A., L. Polsky, M. Kaur, and R. L. A. Cerri. 2018. Effect of estrous expression on timing and failure of ovulation of Holstein dairy cows using automated activity monitors. J. Dairy Sci. 101:11310-11320. https://doi.org/10.3168/jds.2018-15151.

Cerri, R. L. A., H. M. Rutigliano, R. C. Chebel, and J. E. P. Santos. 2009. Period of dominance of the ovulatory follicle influences embryo quality in lactating dairy cows. Reproduction 137:813-823. https://doi.org/10.1530/REP-08-0242.

Chebel, R. C., D. G. B. Demétrio, and J. Metzger. 2008. Factors affecting success of embryo collection and transfer in large dairy herds. Theriogenology 69:98-106. https://doi.org/10.1016/j theriogenology.2007.09.008.

Demetrio, D. G. B., R. M. Santos, C. G. B. Demetrio, and J. L. M. Vasconcelos. 2007. Factors affecting conception rates following artificial insemination or embryo transfer in lactating Holstein cows. J. Dairy Sci. 90:5073-5082. https://doi.org/10.3168/jds.2007 -0223 .

Denis-Robichaud, J., S. J. LeBlanc, A. Jones-Bitton, B. F. Silper, and R. L. Aoki Cerri. 2018. Pilot study to evaluate the association between the length of the luteal phase and estrous activity detected by automated activity monitoring in dairy cows. Front. Vet. Sci. 5:210. https://doi.org/10.3389/fvets.2018.00210.

Dohoo, I., W. Martin, and H. Stryhn. 2009. Veterinary Epidemiologic Research. AVC Inc.

Drost, M., J. D. Ambrose, M. J. Thatcher, C. K. Cantrell, K. E. Wolfsdorf, J. F. Hasler, and W. W. Thatcher. 1999. Conception rates after artificial insemination or embryo transfer in lactating dairy cows during summer in Florida. Theriogenology 52:1161-1167. https://doi.org/10.1016/S0093-691X(99)00208-3.

Duby, R. T., J. L. Hill, D. O'Callaghan, E. W. Overstrom, and M. P. Boland. 1997. Changes induced in the bovine zona pellucida by ovine and bovine oviducts. Theriogenology 47:332. https://doi .org/10.1016/S0093-691X(97)82459-4.

Edmonson, A. J., I. J. Lean, L. D. Weaver, T. Farver, and G. Webster. 1989. A Body Condition Scoring Chart for Holstein Dairy Cows. J. Dairy Sci. 72:68-78. https://doi.org/10.3168/jds.S0022 -0302(89) 79081-0.

Erdem, H., T. Karasahin, H. Alkan, S. Dursun, F. Satilmis, and M. Guler. 2020. Effect of embryo quality and developmental stages on pregnancy rate during fresh embryo transfer in beef heifers. Trop. Anim. Health Prod. 52:2541-2547. https://doi.org/10.1007/ s11250-020-02287-6.

FASS. 2010. Guide for the Care and Use of Agricultural Animals in Research and Teaching. 3rd ed. Federation of Animal Science Societies.

Ferraz, P. A., C. Burnley, J. Karanja, A. Viera-Neto, J. E. P. Santos, R. C. Chebel, and K. N. Galvão. 2016. Factors affecting the success of a large embryo transfer program in Holstein cattle in a commercial herd in the southeast region of the United States. Theriogenology 86:1834-1841. https://doi.org/10.1016/j.theriogenology .2016.05.032.

Hansen, P. J. 2007. To be or not to be-Determinants of embryonic survival following heat shock. Theriogenology 68:S40-S48. https:/ /doi.org/10.1016/j.theriogenology.2007.03.013.

Hasler, J. F. 2001. Factors affecting frozen and fresh embryo transfer pregnancy rates in cattle. Theriogenology 56:1401-1415. https:// doi.org/10.1016/S0093-691X(01)00643-4.

Hasler, J. F. 2014. Forty years of embryo transfer in cattle: A review focusing on the journal Theriogenology, the growth of the industry in North America, and personal reminisces. Theriogenology 81:152-169. https://doi.org/10.1016/j.theriogenology.2013.09.010.

Jaton, C., A. Koeck, M. Sargolzaei, F. Malchiodi, C. A. Price, F. S. Schenkel, and F. Miglior. 2016. Genetic analysis of superovulatory response of Holstein cows in Canada. J. Dairy Sci. 99:3612-3623. https://doi.org/10.3168/jds.2015-10349.

Jaton, C., F. S. Schenkel, T. C. S. Chud, F. Malchiodi, M. Sargolzaei, C. A. Price, A. Canovàs, C. Baes, and F. Miglior. 2019. Genetic 
and genomic analyses of embryo production in dairy cattle. Reprod. Fertil. Dev. 32:50-55. https://doi.org/10.1071/RD19275.

Jinks, E. M., M. F. Smith, J. A. Atkins, K. G. Pohler, G. A. Perry, M. D. MacNeil, A. J. Roberts, R. C. Waterman, L. J. Alexander, and T. W. Geary. 2013. Preovulatory estradiol and the establishment and maintenance of pregnancy in suckled beef cows. J. Anim. Sci. 91:1176-1185. https://doi.org/10.2527/jas.2012-5611.

Leibo, S. P., and N. M. Loskutoff. 1993. Cryobiology of in vitro-derived bovine embryos. Theriogenology 39:81-94. https://doi.org/ 10.1016/0093-691X(93)90025-Z.

Lopez, H., L. Satter, and M. C. Wiltbank. 2004. Relationship between level of milk production and estrous behavior of lactating dairy cows. Anim. Reprod. Sci. 81:209-223. https://doi.org/10.1016/j .anireprosci.2003.10.009.

López-Gatius, F., P. Santolaria, I. Mundet, and J. L. Yániz. 2005. Walking activity at estrus and subsequent fertility in dairy cows. Theriogenology 63:1419-1429. https://doi.org/10.1016/j .theriogenology.2004.07.007.

Løvendahl, P., and M. G. G. Chagunda. 2010. On the use of physical activity monitoring for estrus detection in dairy cows. J. Dairy Sci. 93:249-259. https://doi.org/10.3168/jds.2008-1721.

Lyimo, Z. C., M. Nielen, W. Ouweltjes, T. A. Kruip, and F. J. van Eerdenburg. 2000. Relationship among estradiol, cortisol and intensity of estrous behavior in dairy cattle. Theriogenology 53:17831795. https://doi.org/10.1016/S0093-691X(00)00314-9.

Madureira, A. M. L., T. A. Burnett, J. L. M. Vasconcelos, and R. L. A. Cerri. 2018. Impact of estrous expression on progesterone concentrations and its association with fertility. J. Dairy Sci. 101(Suppl. 2):83 (Abstr.)

Madureira, A. M. L., L. B. Polsky, T. A. Burnett, B. F. Silper, S. Soriano, A. F. Sica, K. G. Pohler, J. L. M. Vasconcelos, and R. L. A. Cerri. 2019. Intensity of estrus following an estradiol-progesterone-based ovulation synchronization protocol influences fertility outcomes. J. Dairy Sci. 102:3598-3608. https://doi.org/10.3168/ jds.2018-15129.

Madureira, A. M. L., B. F. Silper, T. A. Burnett, L. Polsky, L. H. Cruppe, D. M. Veira, J. L. M. Vasconcelos, and R. L. A. Cerri. 2015. Factors affecting expression of estrus measured by activity monitors and conception risk of lactating dairy cows. J. Dairy Sci. 98:7003-7014. https://doi.org/10.3168/jds.2015-9672.

Mann, G. E., M. D. Fray, and G. E. Lamming. 2006. Effects of time of progesterone supplementation on embryo development and interferon- $\tau$ production in the cow. Vet. J. 171:500-503. https:// doi.org/10.1016/j.tvjl.2004.12.005.

NRC. 2001. Nutrient Requirements for Dairy Cattle. Natl. Acad. Sci.

Palmer, M. A., G. Olmos, L. A. Boyle, and J. F. Mee. 2012. A comparison of the estrous behavior of Holstein-Friesian cows when cubicle-housed and at pasture. Theriogenology 77:382-388. https:/ /doi.org/10.1016/j.theriogenology.2011.08.010.

Pereira, M. H. C., M. C. Wiltbank, L. F. S. P. Barbosa, W. M. Costa Jr., M. A. P. Carvalho, and J. L. M. Vasconcelos. 2015. Effect of adding a gonadotropin-releasing-hormone treatment at the beginning and a second prostaglandin F2 $\alpha$ treatment at the end of an estradiol-based protocol for timed artificial insemination in lactating dairy cows during cool or hot seasons of the year. J. Dairy Sci. 98:947-959. https://doi.org/10.3168/jds.2014-8523.

Pereira, M. H. C., M. C. Wiltbank, and J. L. M. Vasconcelos. 2016. Expression of estrus improves fertility and decreases pregnancy losses in lactating dairy cows that receive artificial insemination or embryo transfer. J. Dairy Sci. 99:2237-2247. https://doi.org/10 $.3168 /$ jds.2015-9903.

Pollard, J. W., and S. P. Leibo. 1994. Chilling sensitivity of mammalian embryos. Theriogenology 41:101-106. https://doi.org/10 .1016/S0093-691X(05)80054-8.

Rivera, F., C. Narciso, R. Oliveira, R. L. A. Cerri, A. Correa-Calderón, R. C. Chebel, and J. E. P. Santos. 2010. Effect of bovine somatotropin $(500 \mathrm{mg})$ administered at ten-day intervals on ovulatory responses, expression of estrus, and fertility in dairy cows. J. Dairy Sci. 93:1500-1510. https://doi.org/10.3168/jds.2009-2489.

Rivera, F. A., L. G. D. Mendonça, G. Lopes, J. E. P. Santos, R. V. Perez, M. Amstalden, A. Correa-Calderón, and R. C. Chebel.
2011. Reduced progesterone concentration during growth of the first follicular wave affects embryo quality but has no effect on embryo survival post transfer in lactating dairy cows. Reproduction 141:333-342. https://doi.org/10.1530/REP-10-0375.

Roelofs, J., F. López-Gatius, R. H. F. Hunter, F. J. C. M. van Eerdenburg, and C. Hanzen. 2010. When is a cow in estrus? Clinical and practical aspects. Theriogenology 74:327-344. https://doi.org/10 .1016/j.theriogenology.2010.02.016.

Roelofs, J. B., F. J. C. M. van Eerdenburg, N. M. Soede, and B. Kemp. 2005. Various behavioral signs of estrous and their relationship with time of ovulation in dairy cattle. Theriogenology 63:13661377. https://doi.org/10.1016/j.theriogenology.2004.07.009.

Santos, J. E. P., C. D. Narciso, F. Rivera, W. W. Thatcher, and R. C. Chebel. 2010. Effect of reducing the period of follicle dominance in a timed artificial insemination protocol on reproduction of dairy cows. J. Dairy Sci. 93:2976-2988. https://doi.org/10.3168/jds.2009 -2870 .

Slimane, W., Y. Heyman, Y. Lavergne, P. Humblot, and J. P. Renard. 2000. Assessing chromosomal abnormalities in two-cell bovine in vitro-fertilized embryos by using fluorescent in situ hybridization with three different cloned probes. Biol. Reprod. 62:628-635. https://doi.org/10.1095/biolreprod62.3.628.

Spell, A. R., W. E. Beal, L. R. Corah, and G. C. Lamb. 2001. Evaluating recipient and embryo factors that affect pregnancy rates of embryo transfer in beef cattle. Theriogenology 56:287-297. https:/ /doi.org/10.1016/S0093-691X(01)00563-5.

Stevenson, J. S., and J. H. Britt. 2017. A 100-Year Review: Practical female reproductive management. J. Dairy Sci. 100:10292-10313. https://doi.org/10.3168/jds.2017-12959.

Stringfellow, D. A., and M. D. Givens. 2010. Manual of the International Embryo Transfer Society. 4th ed. International Embryo Transfer Society

Tippenhauer, C. M., J. Plenio, A. Madureira, R. Cerri, W. Heuwieser, and S. Borchardt. 2021a. Timing of artificial insemination using fresh or frozen semen after automated activity monitoring of estrus in lactating dairy cows. J. Dairy Sci. 104:3585-3595. https://doi .org/10.3168/jds.2020-19278.

Tippenhauer, C. M., J. L. Plenio, A. M. L. Madureira, R. L. A. Cerri, W. Heuwieser, and S. Borchardt. 2021b. Factors associated with estrous expression and subsequent fertility in lactating dairy cows using automated activity monitoring. J. Dairy Sci. 104:6267-6282. https://doi.org/10.3168/jds.2020-19578.

Van Soom, A., I. Van Vlaenderen, A. R. Mahmoudzadeh, H. Deluyker, and A. de Kruif. 1992. Compaction rate of in vitro fertilized bovine embryos related to the interval from insemination to first cleavage. Theriogenology 38:905-919. https://doi.org/10.1016/0093 -691X(92)90165-N.

Van Vliet, J. H., and F. J. C. M. Van Eerdenburg. 1996. Sexual activities and oestrus detection in lactating Holstein cows. Appl. Anim. Behav. Sci. 50:57-69. https://doi.org/10.1016/0168-1591(96)01068 -4 .

Vasconcelos, J. L. M., D. G. B. Demétrio, R. M. Santos, J. R. Chiari, C. A. Rodrigues, and O. G. Sá Filho. 2006. Factors potentially affecting fertility of lactating dairy cow recipients. Theriogenology 65:192-200. https://doi.org/10.1016/j.theriogenology.2005.09.030.

Vasconcelos, J. L. M., D. T. G. Jardina, O. G. Sá Filho, F. L. Aragon, and M. B. Veras. 2011. Comparison of progesterone-based protocols with gonadotropin-releasing hormone or estradiol benzoate for timed artificial insemination or embryo transfer in lactating dairy cows. Theriogenology 75:1153-1160. https://doi.org/10.1016/j .theriogenology.2010.11.027.

Vasconcelos, J. L. M., S. Sangsritavong, S. J. Tsai, and M. C. Wiltbank. 2003. Acute reduction in serum progesterone concentrations after feed intake in dairy cows. Theriogenology 60:795-807. https: //doi.org/10.1016/S0093-691X(03)00102-X.

Viuff, D., L. Rickords, H. Offenberg, P. Hyttel, B. Avery, T. Greve, I. Olsaker, J. L. Williams, H. Callesen, and P. D. Thomsen. 1999. A high proportion of bovine blastocysts produced in vitro are mixoploid. Biol. Reprod. 60:1273-1278. https://doi.org/10.1095/ biolreprod60.6.1273. 
Wiltbank, M., H. Lopez, R. Sartori, S. Sangsritavong, and A. Gümen. 2006. Changes in reproductive physiology of lactating dairy cows due to elevated steroid metabolism. Theriogenology 65:17-29. https://doi.org/10.1016/j.theriogenology.2005.10.003.

Wiltbank, M. C., A. H. Souza, J. O. Giordano, A. B. Nascimento, J. M. Vasconcelos, M. H. C. Pereira, P. M. Fricke, R. S. Surjus, F. C. S. Zinsly, P. D. Carvalho, R. W. Bender, and R. Sartori. 2012. Positive and negative effects of progesterone during timed AI protocols in lactating dairy cattle. Anim. Reprod. 9:231-241.

Woelders, H., T. van der Lende, A. Kommadath, M. F. W. te Pas, M.A. Smits, and L. M. T. E. Kaal. 2014. Central genomic regulation of the expression of oestrous behaviour in dairy cows: A review. Animal 8:754-764. https://doi.org/10.1017/S1751731114000342.

Wright, R. W. Jr., and J. Ellington. 1995. Morphological and physiological differences between in vivo- and in vitro-produced preimplantation embryos from livestock species. Theriogenology 44:1167-1189. https://doi.org/10.1016/0093-691X(95)00327-5.

\section{ORCIDS}

A. M. L. Madureira ๑ https://orcid.org/0000-0001-9696-8478

T. A. Burnett (1) https://orcid.org/0000-0003-2417-4016

J. C. S. Marques (ํ) https://orcid.org/0000-0001-9690-2567

A. L. Moore ( https://orcid.org/0000-0003-3132-2347

S. Borchardt (1) https://orcid.org/0000-0003-3937-5777

W. Heuwieser ๑ https://orcid.org/0000-0003-1434-7083

J. L. M. Vasconcelos @ https://orcid.org/0000-0001-6324-3614

C. F. Baes (ํ) https://orcid.org/0000-0001-6614-8890

R. L. A. Cerri ๑ https://orcid.org/0000-0002-8169-8900 